\title{
The Determinants of an Econometric Demand Model for Beverages
}

\author{
Submitted 13/01/20, $1^{\text {st }}$ revision $26 / 01 / 20,2^{\text {nd }}$ revision $18 / 02 / 20$, accepted $09 / 03 / 20$
}

\author{
Toan Ngoc Nguyen ${ }^{1}$
}

\begin{abstract}
:
Purpose: The study attempts to explore the determinants of demand for alcoholic and other beverages to see how a rise in prices of alcohol and other beverages and in household expenditure would influence demand. From the results, we discuss the effectiveness of a prospective excise tax increase on demand for alcoholic and other beverages.

Design/Methodology/Approach: We use the Almost Ideal Demand System to analyze the demand for alcoholic and other beverages. A two-stage estimation approach is employed to estimate the model with data from Vietnam Households Living Standard survey in 2016. In the first stage, we model the choice of consuming or not consuming by a probit regression model. In the second stage, we estimate the demand system by seemingly unrelated regression (SUR).

Findings: We find that demand for beer, other alcoholic beverages, and non-alcoholic packed drinks is elastic to own-price. However, as demand for beer and non-alcoholic packed drinks is also elastic to income, consumption would rise as income grows.

Practical implications: Our findings have significant implications for policymakers and beverage producers. The findings suggest that an increase in excise tax would be an effective solution to control demand for alcoholic beverages. Beverage producers could also use the results to design pricing strategies and forecast consumer behaviors.

Originality/Value: We contribute new findings to the literature of beverage demand analyses. Our findings differ from those in previous studies in the context of both developed and developing countries, which show that demand for alcoholic beverages is inelastic to own-prices. The findings have important implications for policymakers and beverage producers.
\end{abstract}

Keywords: Alcoholic and other beverage demand; demand elasticity; AIDS model, excise tax, Vietnam.

JEL Codes: D12, R22.

Paper Type: Research Paper.

${ }^{1}$ Lecturer, Hochiminh Academy of Politics, toankyoto@gmail.com 


\section{Introduction}

Consumption of beer, other alcoholic beverages, and non-alcoholic packed drinks has been rising rapidly in Vietnam in the past decade. Manthey et al. (2019) show that adult per-capita alcohol consumption in Vietnam has increased to 8.9 liters, an $89.4 \%$ growth from that of 2010. This is the fastest rise in alcohol consumption among 149 countries in their study. Kirin's global beer production report by country in 2017 reveals that, compared to 2007, Vietnam's beer consumption has grown by 209.4 percent and its rank among largest beer production countries has jumped from number 25 to number 9 (Kirin Holdings, 2017). While domestic and foreign beverage producers might be excited by the promising market, it is generally perceived by policymakers and the public that consumption of alcoholic beverages and some of the non-alcohol packed beverages is unhealthy and should be controlled. In fact, imposing higher excise tax rates on alcoholic and carbonated soft drinks has been considered in recent years. Vietnam Ministry of Finance has drafted an amendment to current excise tax regulation for an increase of 10 to 15 percentage points in excise tax rates on these beverages. However, Forgaty (2010) surveyed a number of studies on alcohol demand elasticity and found that demand for alcoholic beverages in many countries is inelastic to own price. Kumar (2017), Tian and Liu (2011) confirmed this finding in developing countries such as India and China. Therefore, the imposition of excise tax on alcoholic beverages and non-alcoholic packed drinks might not be effective in controlling consumption. Other researhers have proposed models for convergence in several sectors (Katrakilidis et al., 2017; Thalassinos et al., 2012).

This paper aims to examine household demand for alcoholic and non-alcoholic packed beverages in Vietnam and identify its determinants. Our hypothesis is that household demand for alcoholic beverages and non-alcoholic packed drinks is elastic to own-prices and expenditure and, therefore, it might be feasible to use excise tax to influence the consumption. We analyze demand for alcoholic and other beverages using the Almost Ideal Demand System (AIDS), first introduced by Deaton and Muellbauer (1980). AIDS is a favorable model to study demand system and there have been several studies using the model to analayze demand for beverages. For instance, Janda et al. (2010) applied AIDS model to estimate the demand for alcoholic beverages in Czech Republic to discuss the potential impact of a tax intervention. Eakins and Gallagher (2003) employed 3 versions of AIDS model to estimate demand elasticity of beer, spirits and wine in Ireland. In Vietnam, we find some studies estimating demand elasticity using AIDS framework such as Le (2008) and $\mathrm{Vu}$ (2009). However, these studies focused mainly on foods such as rice and pork rather than beverages.

In this research, we focus on demand for a few types of beverages: beer, other alcoholic beverages and non-alcoholic packed drinks. To analyze the interdependence in demand between beverages, we also include coffee powder, dried tea and fresh milk. To deal with the problem of dependent variable censorship, 
the two-stage estimating procedure like Heien and Wessels (1990) is employed. In the first stage, the consume-or-not decision is estimated by a probit regression model. The decision is assumed to be dependent on price, total expenditure, and a number of demographic variables. Inverse Mills ratios obtained from the first stage is used as the instrumental variable in the second stage equations, in which we regress the share of each beverage expenditure to total expenditure on own-price, cross prices and other household demographic variables. We find that demand for beer, other alcoholic beverages and non-alcohol packed drinks is elastic to ownprices.

The finding implies that using excite tax to control alcohol consumption can be a good measure. However, we show that the measure might only slowdown the increase in consumption. Since demand for beer and non-alcoholic beverages is also elastic to income, consumption would increase significantly if income rises.

The remainder of the paper is structured as follows. In section 2, we briefly describe the model and data. Section 3 analyzes estimation results and discusses findings. The final section is, as usual, concluding remarks.

\section{Research Methods and Data}

The simplest approach to estimate demand elasticity is that of Working (1943), which considers expenditure share of a good consumed as a linear function of all good prices and total expenditure in log form. This model is, however, unable to analyze the interdependence in the consumption of goods. A complete demand system is required to model concurrent choices of goods consumed. The first of such a demand system is the Linear Expenditure System (LES) by Stone (1954). The drawback of the LES model is that it cannot be used with inferior goods and that it implies a linear Engel function, which is contrary to theory. Moreover, Barten (1969) proved that LES model also fails to satisfy homogeneity, symmetry and adding-up properties of a complete demand system. Other demand system models have been subsequently suggested with improved features, such as the Rotterdam model (Theil, 1965; 1976; Barten, 1969) and the translog model (Christensen et al, 1975).

In this paper, we employ the Almost Ideal Demand System (AIDS) by Deaton and Muellbauer (1980). The advantages of AIDS model are: it satisfies the axioms of choice; it aggregates perfectly over consumers without assuming linear Engel function; it facilitates the imposition of homogeneity, symmetry and adding-up restrictions. The model is expressed as follow:

$$
\mathrm{w}_{i}=\alpha_{i}+\beta_{i} \ln (\mathrm{B} / P)+\sum_{j}^{S} \gamma_{\mathrm{ij}} \ln \left(p_{j}\right)+\varepsilon_{i}(1)
$$


Where the price index $\mathrm{P}$ is defined as:

$$
\ln P=\alpha_{0}+\sum_{k}^{S} \alpha_{k} \ln \left(p_{k}\right)+\frac{1}{2} \sum_{k}^{S} \sum_{l}^{S} \gamma_{k l} \ln \left(p_{k}\right) \ln \left(p_{l}\right)(2)
$$

The above price index is, however, non-linear and $\alpha_{0}$ is not estimable. Deaton and Muellbauer (1980) proposed to approximate the non-linear price index P by a linear index price $P^{*}=P / \omega$ and $\ln \left(P^{*}\right)=\sum_{i=1}^{S} w_{i} \ln \left(p_{i}\right)$, where $E(\ln (\omega))=\alpha_{0}$. The AIDS model is then rewritten in linear approximate form (LA/AIDS) as:

$$
\mathrm{w}_{i}=\alpha_{i}^{*}+\beta_{i} \ln \left(\mathrm{B} / P^{*}\right)+\sum_{j}^{S} \gamma_{\mathrm{ij}} \ln \left(p_{j}\right)+\varepsilon_{i}^{*}(3)
$$

With $\alpha_{i}^{*}=\alpha_{i}-\beta_{i} \ln (\omega)$.

While price and real expenditure are often regarded as important factors influencing demand for a good, other factors such as household demographic characteristics might come into play (Heien and Wessels, 1988; Kinnucan, 1986). Pollak and Wales (1978) suggested adding demographic variables using translating approach to ensure the linearity of the model. Accodingly, the LA/AIDS model with demographic variables becomes:

$$
\mathrm{w}_{i}=\alpha_{i}^{*}+\beta_{i} \ln \left(\mathrm{B} / P^{*}\right)+\sum_{j=1}^{S} \gamma_{\mathrm{ij}} \ln \left(p_{j}\right)+\sum_{k=1}^{K} \delta_{i k} d_{k}+\varepsilon_{i}^{*}(4)
$$

Where $d_{k}$ is a demographic variable $(\mathrm{k}=1, . ., \mathrm{K})$.

To ensure homogeneity and symmetry properties, the following restrictions must be imposed: $\sum_{k=1}^{S} \gamma_{j k}=0 ; \gamma_{i j}=\gamma_{j i}$. The aggregation restrictions $\sum_{i=1}^{S} \beta_{i}=0, \sum_{i=1}^{S} \gamma_{i j}=0$, and the adding-up properties $\sum_{i=1}^{S} \alpha_{i}=1$ can be imposed by not estimating one equation in the demand system.

While equation (4) is ready for estimation, the non-negativity of the dependent variable might lead to estimation bias. We correct this concern by applying the generalized Amemiya (1974) two-stage regression, which is proved by Lee (1978) to be asymptotically more efficient than alternatives such as Heckman (1978) or Nelson and Olsen (1978). Accordingly, in the first stage, the choice of consumption 
is modeled in a probit framework. Prices of goods and other related demographic variables are used as repressors. Inverse Mills ratios (IMRs) computed from the first stage regressions are then used as instruments in the second stage equations:

$$
\mathrm{w}_{i}=\alpha_{i}^{*}+\beta_{i} \ln \left(\mathrm{B} / P^{*}\right)+\sum_{j}^{S} \gamma_{\mathrm{ij}} \ln \left(p_{j}\right)+\sum_{k=1}^{K} \delta_{i k} d_{k}+\lambda_{i} I M R_{i}+\varepsilon_{i}^{*}(5)
$$

Equation (5) can be estimated using iterative seemingly unrelated regression (ISUR). Elasticity can be derived, as shown by Green and Alston (1990) and Buse (1994), as:

Own-price elasticity: $e_{i i}^{u}=-1+\left[\frac{\gamma_{i i}}{\bar{w}_{i}}\right]-\beta_{i}$;

Cross-price elasticity: $e_{i j}^{u}=\left[\frac{\gamma_{i j}}{\bar{w}_{i}}\right]-\left[\frac{\beta_{i}}{\bar{w}_{i}}\right] \bar{w}_{j}$;

Income elasticity: $e_{i}=1+\left[\frac{\beta_{i}}{w_{i}}\right]$

Where $\bar{w}_{i}$ is the average share of good $i$ consumption in total expenditure.

The above model is used to examine demand for alcohol and other beverages in Vietnam. We use a dataset of 9,399 households extracted from the Vietnam Household Living Standard Survey 2016. Due to availability of data, six types of beverages are considered: beer, other alcoholic beverages, non-alcoholic packed drinks, coffee powder, dried tea and fresh milk. Other alcoholic beverages are the mixture of local and foreign wine and sprits. Non-alcoholic packed drinks comprise of various types of packed drinks such as bottled water, carbonated drinks, packed juices, tonic, etc. We add coffee powder and dried tea since they are traditional Vietnamese drinks and may be considered in beverage purchase decision of consumers. Fresh milk is added mainly because we need a not-estimated equation.

It is necessary to note that our data capture only alcoholic and other beverage consumption at home and exclude outside consumption, such as in restaurants or pubs. A number of demographic variables are also put in the model including household characteristics such as household size, dependency ratio and characteristics of household head, such as age, gender, ethnicity and the number of years in school. We also include location dummies to examine if households in different geographical regions or in urban/rural areas exhibit different demand patterns for alcoholic and other beverages. Using common division of geographical regions in Vietnam, 8 different regions are selected: Northwest, Northeast, Red river 
delta, Northern Central, Central Highland, Southern Central Coast, Southeast and Southwest. The Northeast region is used as the base. The list of variables used is shown in Table 1.

\section{Results and Discussion}

We report the results of the two-stage estimation in Table 2 and Table 3. Table 2 presents the results of six probit regressions on the decision to consume beverages. We can see that the probability to consume each of the beverages in our study is negatively related to own-price, as suggested by theory. Households are more likely to buy a type of beverage if prices of other beverages increase, except for the case of dried tea. It is interesting that the decision to consume dried tea is negatively influenced by the prices of other beverages, as if they are supplements rather than substitutes.

Beverage consumption decision is also positively influenced by real expenditure as expected, again except for dried tea. Households are less likely to buy dried tea if they have higher expenditure. Demographic variables, such as household size, dependency ratio, ethnicity, age, gender, years of schooling and geographical regions also appear to be determinants of consumption decision.

Table 1. List of independent variables used in the models

\begin{tabular}{|c|c|}
\hline Variable & Definition \\
\hline P_beer & Log of beer unit price per liter. \\
\hline P_otheralcohols & Log of other alcoholic beverages' unit price per liter. \\
\hline P_packeddrinks & $\begin{array}{l}\text { Log of unit price per liter of non-alcoholic packed drinks such as bottled water, } \\
\text { tonic, juice, sparking drinks. }\end{array}$ \\
\hline P_coffee & Log of unit price per kilogram of coffee powder. \\
\hline P_tea & Log of unit price per kilogram of dried tea. \\
\hline P_freshmilk & Log of unit price per liter of fresh milk. \\
\hline Expenditure & Log of household real total expenditure on beverage. \\
\hline Hhsize & The number of people in a household. \\
\hline Dependency & The ratio of old people and children in a household. \\
\hline Urban & $\begin{array}{l}\text { Binary variable which is unit if a household is in urban regions and zero } \\
\text { otherwise. }\end{array}$ \\
\hline Ethnicity & Binary variable which is unity if a household's head is of ethnic minority. \\
\hline Age & Log of age of Household head. \\
\hline Gender & Binary variable which is unity if household head is male and zero otherwise. \\
\hline Schooling & Log of the number of schooling years of household head. \\
\hline Northwest & $\begin{array}{l}\text { Binary variable which is unity if a household is in the Northwest region and zero } \\
\text { otherwise. }\end{array}$ \\
\hline Redriver & $\begin{array}{l}\text { Binary variable which is unity if a household is in the Red river region and zero } \\
\text { otherwise. }\end{array}$ \\
\hline Notherncentral & $\begin{array}{l}\text { Binary variable which is unity if a household is in the Red river delta region and } \\
\text { zero otherwise. }\end{array}$ \\
\hline Highland & $\begin{array}{l}\text { Binary variable which is unity if a household is in the Central Highland region } \\
\text { and zero otherwise. }\end{array}$ \\
\hline
\end{tabular}




\begin{tabular}{|l|l|}
\hline Centralcoast & $\begin{array}{l}\text { Binary variable which is unity if a household is in the Southern Central Coast } \\
\text { region and zero otherwise. }\end{array}$ \\
\hline Southeast & $\begin{array}{l}\text { Binary variable which is unity if a household is in the Southeast region and zero } \\
\text { otherwise. }\end{array}$ \\
\hline Southwest & $\begin{array}{l}\text { Binary variable which is unity if a household is in the Southwest region and zero } \\
\text { otherwise. }\end{array}$ \\
\hline
\end{tabular}

Table 3 shows estimation results of the AIDS equation in the second stage, except for the equation of fresh milk, which is not estimated. It tells us that the allocation of expenditure on each beverage depends negatively on own-price and positively on cross-prices with the exception of dried tea. Dried tea consumption is positively related to own-price, though significant level is only at 10 percent. Tea consumption is also negatively related to cross-prices of other alcoholic beverages, non-alcoholic packed drinks and fresh milk, as if they are complementary goods. Expenditure also comes into play with mixed effects on beverage consumption. Consumption of beer and non-alcohol packed drinks appears to be positively correlated to real expenditure. On the contrary, households tend to allocate smaller shares of expenditure on coffee powder and dried tea when they get richer. The above findings are confirmed by the analysis of demand elasticities in Table 4 and Table 5.

Table 2. Result of probit regression in the first stage

\begin{tabular}{|c|c|c|c|c|c|c|}
\hline Variable & Beer & $\begin{array}{l}\text { Other } \\
\text { Alcohols }\end{array}$ & $\begin{array}{l}\text { Non- alcohol } \\
\text { packed drinks }\end{array}$ & $\begin{array}{l}\text { Coffee } \\
\text { Powder }\end{array}$ & Dried tea & $\begin{array}{l}\text { Fresh } \\
\text { milk }\end{array}$ \\
\hline P_beer & $-0.8 * * *$ & 0.02 & $0.18 * *$ & 0.25 & $-0.2 * *$ & $0.34 * * *$ \\
\hline P_otheralcohol & $0.22 * * *$ & $-0.61 * * *$ & $0.28 * * *$ & $0.35 * * *$ & 0.03 & $0.22 * *$ \\
\hline P_packeddrink & $0.31 * * *$ & $0.14 * * *$ & $-0.37 * * *$ & 0.02 & $-0.05 * * *$ & $0.22 * * *$ \\
\hline P_coffee & -0.13 & 0.01 & -0.07 & $-0.91 * * *$ & $-0.25 * * *$ & 0.08 \\
\hline P_tea & $0.18 * * *$ & 0.02 & -0.06 & $-0.11 * *$ & $-0.52 * * *$ & $0.1 * *$ \\
\hline P_freshmilk & $0.37 * * *$ & $0.16 * *$ & $0.21 * * *$ & -0.11 & $-0.17 * *$ & $-0.58 * * *$ \\
\hline Realexpense & $0.77 * * *$ & $0.25 * * *$ & $0.48 * * *$ & $0.04 * *$ & $-0.28 * * *$ & $0.48 * * *$ \\
\hline Hhsize & $0.03 *$ & $0.07 * * *$ & $-0.04 * *$ & $0.1 * * *$ & $0.12 * * *$ & $0.05 * * *$ \\
\hline Dependency & $-0.15 * * *$ & $-0.16 * * *$ & -0.02 & $-0.06 * *$ & $-0.08 * * *$ & $0.29 * * *$ \\
\hline Ethnicity & $-0.31 * * *$ & $0.44 * * *$ & -0.08 & $-0.23 * *$ & $-0.44 * * *$ & $-0.5 * * *$ \\
\hline Age & $0.2 * *$ & $0.14 *$ & 0.06 & $0.47 * * *$ & $0.82 * * *$ & $-0.47 * * *$ \\
\hline Gender & $0.13 * *$ & $0.49 * * *$ & $-0.14 * * *$ & 0.03 & $0.39 * * *$ & $-0.29 * *$ \\
\hline Schooling & $0.22 * * *$ & $-0.17 * * *$ & 0.02 & $0.14 * * *$ & $0.11 * * *$ & $0.13 * * *$ \\
\hline Urban & $0.15 * * *$ & $-0.3 * * *$ & $0.08 *$ & $0.17 * * *$ & $-0.14 * * *$ & $0.13 * * *$ \\
\hline Northwest & $-0.54 *$ & $1.32 * * *$ & $-0.65 * * *$ & $-0.54 *$ & -0.18 & $-0.66 * * *$ \\
\hline Redriver & $0.38 * * *$ & $0.99 * * *$ & $-0.4 * * *$ & $-0.96 * * *$ & $0.62 * * *$ & -0.04 \\
\hline Notherncentral & -0.005 & $0.72 * * *$ & $-0.43 * * *$ & $-1.24 * * *$ & -0.06 & 0.14 \\
\hline Centralhighland & -0.11 & $0.47 * * *$ & -0.007 & $-0.25 * *$ & $-0.23 * * *$ & $-0.27 * * *$ \\
\hline Southerncentral & 0.04 & -0.07 & $0.16 *$ & $-0.71 * * *$ & $-0.17 * *$ & 0.05 \\
\hline Southeast & 0.13 & 0.01 & $0.2 * *$ & $-0.3 * * *$ & $-0.36 * * *$ & $-0.21 * *$ \\
\hline Southwest & -0.14 & 0.1 & $-0.51 * * *$ & 0.13 & -0.11 & $-0.14^{*}$ \\
\hline Constant & -3.78 & -0.74 & -1.39 & -0.22 & 1.65 & -0.7 \\
\hline $\mathrm{R} 2$ & 0.3 & 0.16 & 0.25 & 0.16 & 0.14 & 0.26 \\
\hline
\end{tabular}


Note: $* * *_{-}$significant at $1 \% ; * *_{-}$significant at $5 \% ; *_{-}$significant at $10 \%$.

Table 4 presents results of own-price and income elasticity estimates. All elasticity coefficients are statistically significant, except for those of fresh milk, which we do not have statistical inference. The results confirm that the beverages are all normal goods as their demand is negatively related to own-prices. Demand for beer, other alcohols and non-alcohol packed drinks appear relatively elastic to own-price as their elasticities are much higher than unity. Household demand is less sensitive to prices of coffee powder and dried tea. The own-price elasticities of coffee powder and dried tea demand are less than unity. With respect to elasticity to income, we can see that households consider beer and non-alcohol packed drinks as luxury goods as their elasticity to income are more than unity. Income elasticity of other alcohols is nearly unity but note that other alcohols is a mixture of low-price traditional spirits and higher-price foreign varieties. Coffee powder and dried tea are considered as necessity goods since their income elasticity coefficients are lower than unity.

Table 3. Estimation result of second-stage regression

\begin{tabular}{|c|c|c|c|c|c|}
\hline Variable & Beer & $\begin{array}{l}\text { Other } \\
\text { alcoholic } \\
\text { beverages }\end{array}$ & $\begin{array}{l}\text { Non-alcoholic } \\
\text { packed drinks }\end{array}$ & $\begin{array}{l}\text { Coffee } \\
\text { powder }\end{array}$ & Dried tea \\
\hline P_beer & $-0.026 * * *$ & 0.013 & $0.08 * * *$ & $-0.015 * * *$ & 0.01 \\
\hline P_otheralcohol & 0.001 & $-0.057 * * *$ & 0.01 & $0.005^{*}$ & $-0.028 * * *$ \\
\hline P_packeddrink & $0.009 * * *$ & $0.012 * * *$ & $-0.08 * * *$ & 0.002 & $-0.04 * * *$ \\
\hline P_coffee & $0.034 * * *$ & $0.039 * * *$ & $0.064 * * *$ & $0.005 *$ & 0.009 \\
\hline P_tea & $0.009 * *$ & -0.004 & $0.016 * * *$ & 0.003 & $0.01 *$ \\
\hline P_freshmilk & $0.025 * * *$ & $0.041 * * *$ & $0.044 * * *$ & -0.004 & $-0.047 * * *$ \\
\hline Realexpense & $0.024 * * *$ & -0.002 & $0.027 * * *$ & $-0.14 * * *$ & $-0.17 * * *$ \\
\hline Hhsize & $-0.01 * * *$ & -0.005 & $-0.02 * * *$ & $-0.004 * * *$ & $0.009 * * *$ \\
\hline Dependency & $-0.006 * * *$ & $-0.02 * * *$ & -0.005 & 0.0004 & $-0.01 * * *$ \\
\hline Ethnicity & $0.013 *$ & $0.22 * * *$ & $0.028 * * *$ & $0.018 * * *$ & $-0.067 * * *$ \\
\hline Age & $0.017 *$ & $-0.028 * *$ & 0.014 & 0.003 & $0.11 * * *$ \\
\hline Gender & 0.005 & $0.05 * * *$ & $-0.046 * * *$ & -0.0007 & $0.06 * * *$ \\
\hline Schooling & $-0.009 * * *$ & $-0.046 * * *$ & $-0.019 * * *$ & $-0.005 * * *$ & $0.011 * *$ \\
\hline Urban & -0.004 & $-0.034 * * *$ & -0.007 & -0.0004 & $-0.013 *$ \\
\hline Northwest & 0.014 & $0.31 * * *$ & -0.016 & 0.012 & $-0.05 *$ \\
\hline Redriver & $-0.023 * *$ & $0.084 * * *$ & -0.024 & $0.018 * * *$ & $0.03 * *$ \\
\hline Notherncentral & -0.0002 & $0.13 * * *$ & 0.019 & 0.006 & $-0.039 * * *$ \\
\hline Centralhighland & 0.008 & $0.1 * * *$ & $0.042 * * *$ & 0.004 & $-0.031 * *$ \\
\hline Southerncentral & $0.026 * * *$ & 0.018 & $0.034 * *$ & 0.006 & $-0.059 * * *$ \\
\hline Southeast & $0.024 * * *$ & $0.029 *$ & $0.061 * * *$ & 0.005 & $-0.049 * * *$ \\
\hline Southwest & $0.041 * * *$ & $0.053 * * *$ & $-0.042 * * *$ & $0.019 * * *$ & -0.019 \\
\hline IMR & $0.37 * * *$ & $0.24 * * *$ & $0.3 * * *$ & $0.22 * * *$ & 0.016 \\
\hline Constant & -0.26 & -0.065 & -0.64 & -0.008 & 0.22 \\
\hline
\end{tabular}

Note: $* *_{-}$-significant at $1 \% ; *_{-}$significant at $5 \% ; *_{-}$significant at $10 \%$.

Table 4. Own - price and income elasticity coefficients of beverage demand

\begin{tabular}{|l|l|l|}
\hline Type of beverage & Own-price Elasticity & Income Elasticity \\
\hline Beer & $-1.272^{* * *}$ & $1.224 * * *$ \\
\hline Other alcoholic beverages & $-1.267^{* * *}$ & $0.991^{* * *}$ \\
\hline
\end{tabular}




\begin{tabular}{|l|l|l|}
\hline Non-alcoholic packed drinks & $-1.688^{* * *}$ & $1.219^{* * *}$ \\
\hline Coffee Powder & $-0.793^{* *}$ & $0.428^{* * *}$ \\
\hline Dried tea & $-0.788^{* * *}$ & $0.361^{* * *}$ \\
\hline Fresh milk & -1.359 & 1.514 \\
\hline
\end{tabular}

Note: $* *^{*}$-significant at $1 \% ; * *_{-}$significant at $5 \% ; *_{-}$significant at $10 \%$.

The cross-price elasticity coefficients in Table 5 provide additional information on beverage demand. The results do not show the substitution between beer and other alcoholic beverages. Instead, non-alcohol packed drinks, fresh milk and coffee powder are probably substitute goods of beer and alcohols. Dried tea, non-alcoholic drinks, beer and other alcoholic beverages are substitutes of coffee powder.

Table 5. Cross - price elasticity coefficients of beverage demand

\begin{tabular}{|c|c|c|c|c|c|}
\hline Price of & \multicolumn{5}{|c|}{ Elasticity coeffient of demand } \\
\hline & Beer & $\begin{array}{l}\text { Other Alcoholic } \\
\text { Beverages }\end{array}$ & $\begin{array}{l}\text { Non-alcoholic } \\
\text { drinks }\end{array}$ & Coffee & Tea \\
\hline Beer & & 0.065 & $0.643 * * *$ & $-0.509 * * *$ & $0.105 * *$ \\
\hline $\begin{array}{l}\text { Other Alcoholic } \\
\text { beverages }\end{array}$ & -0.046 & & 0.033 & $0.316^{* * *}$ & 0.029 \\
\hline $\begin{array}{l}\text { Non-alcoholic } \\
\text { packed drinks }\end{array}$ & $0.059 * * *$ & $0.057 * * *$ & & $0.141 * * *$ & $-0.073 * * *$ \\
\hline Coffee Powder & $0.31^{* * * *}$ & $0.188 * * *$ & $0.518 * * *$ & & 0.051 \\
\hline Dried Tea & 0.025 & -0.033 & 0.074 & $0.269 * * *$ & \\
\hline Fresh milk & $0.172^{* * *}$ & $0.199 * * *$ & $0.305 * * *$ & 0.123 & -0.005 \\
\hline
\end{tabular}

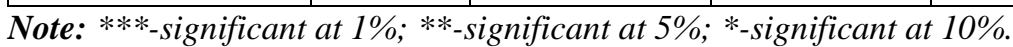

Demographic characteristics also influence demand for beverages. Table 3 reveals that larger households are more likely to have smaller shares of expenditure on beer, non-alcoholic beverages and coffee powder and have bigger shares of expenditure on dried tea. Households with higher dependency ratio tend to spend smaller shares of expenditure on beer, other alcohols and dried tea. Households with heads of ethnic minority tend to allocate more expenditure on the beverages, except for dried tea, which is the traditional drink of the major ethnicity.

Age of household head is also a determinant of the share of expenditure on beverages. Households with older heads would potentially allocate larger shares on beer and dried tea and smaller share on other alcoholic beverages. Households with male head is likely to consume more other alcoholic beverages and dried tea and less non-alcoholic packed drinks. Households with higher education tend to allocate smaller shares of expenditure on beverages, except for dried tea.

Location might be an influent factor as well. Households in urban areas often allocate smaller shares of expenditure on other alcoholic beverages and dried tea. Larger shares of expenditure on alcohol can be seen in the Northwest and Northern Central, while in Southern Central, Southeast and Southwest, households seem to consume more beer. Dried tea is more likely to be consumed in Red River region. Surprisingly, households in Red River and Southwest regions tend to allocate more 
share of expenditure on coffee powder than households elsewhere, probably because they are less likely to drink coffee outside their home.

Our finding that demand for beer and other alcoholic beverages is elastic to ownprice differs from those in some previous studies. In a meta-analysis, Forgaty (2010) showed that estimates of beverage demand elasticity coefficients vary markedly but the mean values are rather small. For example, beer own-price elasticity coefficients vary from 1.28 to -3 with the mean value of -0.44 . $92 \%$ of studies surveyed find own-price inelasticity of demand for beer and the number of wine and spirits are $83 \%$ and $78 \%$ respectively. Income elasticity coefficients also vary among studies.

The mean of income elasticity coefficients of beer demand in Forgaty (2010) survey is 0.64 . The studies in his meta-analysis, however, focused mainly on developed countries. Eakins and Gallagher (2003) also found beer and spirits to be inelastic to price in Ireland. For developing countries, Kumar (2017) and Tian and Liu (2011) confirmed that demand for alcohol is also inelastic to price in India and China, respectively. The difference in findings may come from the fact that beer, other alcoholic beverages and non-alcoholic packed beverages are considered as luxurious goods in Vietnam.

For average households, price is an important factor influencing demand. That makes demand for these beverages sensitive to own-price changes. Our finding about income elasticity is consistent with that of Colen and Swinnen (2010). They proved that beer consumption follows an inverse U-shape pattern. That is, it would increase initially with rising income in developing countries. Then, it would fall when a country reaches higher income levels.

The above findings have important implications for policymakers and beverage producers. First, as demand for beer, other alcoholic beverages and non-alcoholic packed drinks is relatively elastic to own-prices, an increase in excise tax rate would probably drives demand down notably as it will lead to higher prices. In short-run, higher excise tax rates would help control consumption of unhealthy beverages. Second, as demand for these drinks is relatively elastic to income, households tend to consume more beer and non-alcoholic packed drinks when they become richer. As a result, the rise in excise tax rate might not be able to curb consumption of these drinks in medium to long-run as economic growth would push up household income. Third, beer and other alcoholic beverages might not be substitutes and households would choose one or another. In other words, there might be two sets of consumers, one set prefers beer and the other prefer alcoholic beverages.

Since demand for beer is more elastic to income, as income rises, demand for beer would increase faster than demand for other alcoholic beverages. Fourth, there are differences in beverage consumption behaviors among households of different demographic characteristics. The trend of household downsizing implies an increase in beer, non-alcoholic packed drinks and coffee powder. However, as the population 
gets higher education, the consumption of unhealthy drinks would probably decrease. Also, households in different regions show different patterns of beverage demand. Urbanization might lead to a drop in alcohol consumption at home.

\section{Conclusions}

In this paper, we attempt to examine the demand for alcoholic and other beverages in developing country using the linear approximate Almost Ideal Demand System of Deaton and Muellbauer (1980) with the dataset from Vietnam Household Living Standard Survey 2016. The findings show that demand for beer, other alcoholic beverages and non-alcoholic packed drinks is elastic to own-price and an increase in excise tax would be an effective measure to curb consumption. However, if income rises, demand for beer and non-alcoholic packed drinks might continue to increase as their income elasticity coefficients are more than unity. Meanwhile, demand for coffee powder and dried tea appear to be inelastic to own-price and income. We contribute to the literature with new findings from a developing country where income is growing relatively fast.

There are certainly some limitations in this study, however. First, other alcoholic beverages and non-alcoholic packed drinks are mixtures that contain various drinks. Mixing different drinks in groups obviously affects the results. Second, the data in our study include only beverages consumed at home while people today drink a lot outside their home, such as in restaurants or pubs. A tailored survey is needed to get more insights of demand for different drinks.

\section{References:}

Amemiya, T. 1974. Multivariate Regression and Simultaneous Equation Models when the Dependent Variables are Truncated Normal. Econometrica, 42, 999-1012.

Barten, A.P. 1969. Maximum Likelihood Estimation of a Complete System of Demand Equations. European Economic Review, 1, 7-73.

Buse, A. 1994. Evaluating the Linearized Almost Ideal Demand System. American Journal of Agricultural Economics, 76, 781-793.

Christensen, L.R., Jorgenson, D.W., Lau, L.J. 1975. Transcendental Logarithmic Utility Functions. American Economic Review, 65, 367-383.

Colen, L., Swinnen, J. 2010. Beer Drinking Nations: The Determinants of Global Beer Consumption. LICOS Discussion Paper Series. Katholieke Universiteit Leuven, Belgium.

Deaton, A., Muellbauer, J. 1980. An Almost Ideal Demand System. American Economic Review, 70, 312-326.

Eakins, J., Gallagher, L. 2003. Dynamic Almost Ideal Demand System: An Empirical Analysis of Alcohol Expenditure in Ireland. Applied Economics, 35(9), 1025-1036.

Forgarty, J. 2010. The Demand for Beer, Wine and Spirits: A Survey of the Literature. Journal of Economic Survey, 24, 428-478.

Green, R., Alston, J.M. 1990. Elasticities in AIDS models. American Journal Agricultural Economics, 72, 442-445. 
Heckman, J. 1978. Dummy Endogenous Variables in a Simultaneous Equation System, Econometrica, 46, 931-959.

Heien, D., Wessells, C. 1988. Demand for Dairy Products: Structure, Prediction and Decomposition. American Journal of Agricultural Economics, 70, 219-228.

Heien, D., Wessells, C. 1990. Demand System Estimation with Microdata: A Censored Regression Approach. Journal of Business and Economic Statistics, 8(3), 365-371.

Janda, K., Mikolasek, J., Netuka, M. 2010. Complete Almost Ideal Demand System Approach to the Czech Alcohol Demand. Agricultural Economics, 56(9), 421-434.

Katrakilidis, C., Konteos, G., Sariannidis, N. and Manolidou, C. 2017. Investigation of Convergence in the Tourist Markets of Greece. European Research Studies Journal, 20(4A), 707-729.

Kinnucan, H.W. 1986. Demographic vs. Media Advertising Effects on Milk Demand: The Case of New York City Market. Northeastern Journal of Agricultural and Resource Economics, 15, 66-74.

Kirin Holdings. 2017. Global Beer Production by Country in 2017. Kirin Beer Univ Report.

Kumar, S. 2017. Price Elasticity of Alcohol Demand in India. Alcohol and Alcoholism, 52 (3), 390-395.

Le, Q.C. 2008. An Empirical Study of Food Demand in Vietnam. ASEAN Economic Bulletin, 25(3), 283-292.

Lee, L.F. 1978. Simultaneous Equations Models with Discrete and Censored Dependent Variables. In Manski, P. and McFadden, D.L. (Ed.), Structural Analysis of Discrete Data with Econometric Applications, MIT Press, Cambridge, USA, 346-364.

Manthey, J., Shield, K., Rylett, M., Hasan, O., Probst, C., Rehm, R. 2019. Global Alcohol Exposure between 1990 and 2017 and Forecast until 2030: A Modelling Study. The Lancet, 393, 2494-2502.

Nelson, F.D., Olsen, L. 1970. Specification and Estimation of a Simultaneous Equation Model with Limited Dependent Variables. International Economic Review, 19, 695710 .

Pollak, R., Wales, T. 1978. Estimation of Complete Demand System from Household Budget Data: The Linear and Quadratic Demand System. American Economic Review, 68(3), 348-359.

Stone, R. 1954. Linear Expenditure Systems and Demand Analysis: An Application to the Pattern of British Demand. Economic Journal, 64, 511-527.

Thalassinos, I.E., Ugurlu, E. and Muratoglu, Y. 2012. Income Inequality and Inflation in the EU. European Research Studies Journal, 15(1), 127-140.

Theil, H. 1965. The Information Approach to Demand Analysis. Econometrica, 33, 67-87.

Theil, H. 1976. Theory and Measurement of Consumer Demand. North- Holland Publishing.

Tian, Q., Liu, L. 2011. Is the Demand for Alcoholic Beverages in Developing Countries Sensitive to Price? Evidence from China. International Journal of Environmental Research and Public Health, 8(6), 2124-2131.

Vu, H.L. 2009. Estimation of Food Demand from Household Survey Data in Vietnam. Depocen Working paper 12.

Working, H. 1943. Statistical Laws of Family Expenditure. Journal of American Statistics Association, 33, 43-56. 